A NOTE ON THE INTRAVESICAL SEPARATION OF THE URINE FROM EACH KIDNEY.

By B. G. A. MOYNIHAN, M.S., F.R.C.S., Leeds.

The need for some means of obtaining the urine from each kidney separately has long been recognized in surgical work.

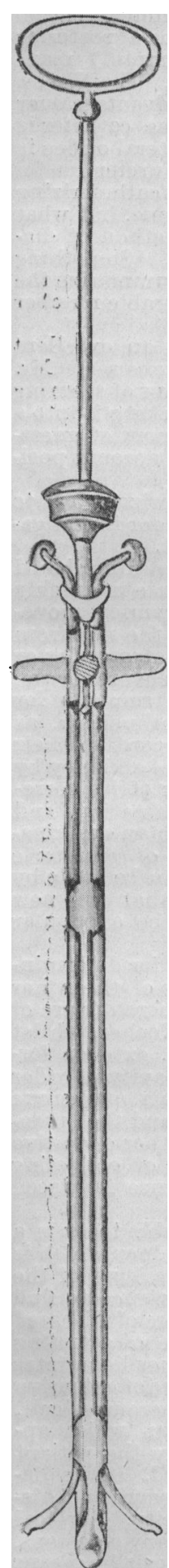

Fig. 3.-The urine separator of of the importance of knowing the exact functional power of each kidney in any form of disease affecting the urinary tract every surgeon can speak. The methods of obtaining the urines from each kidney separately for examination are two, either by catheterizing the ureters, and obtaining the urine be-

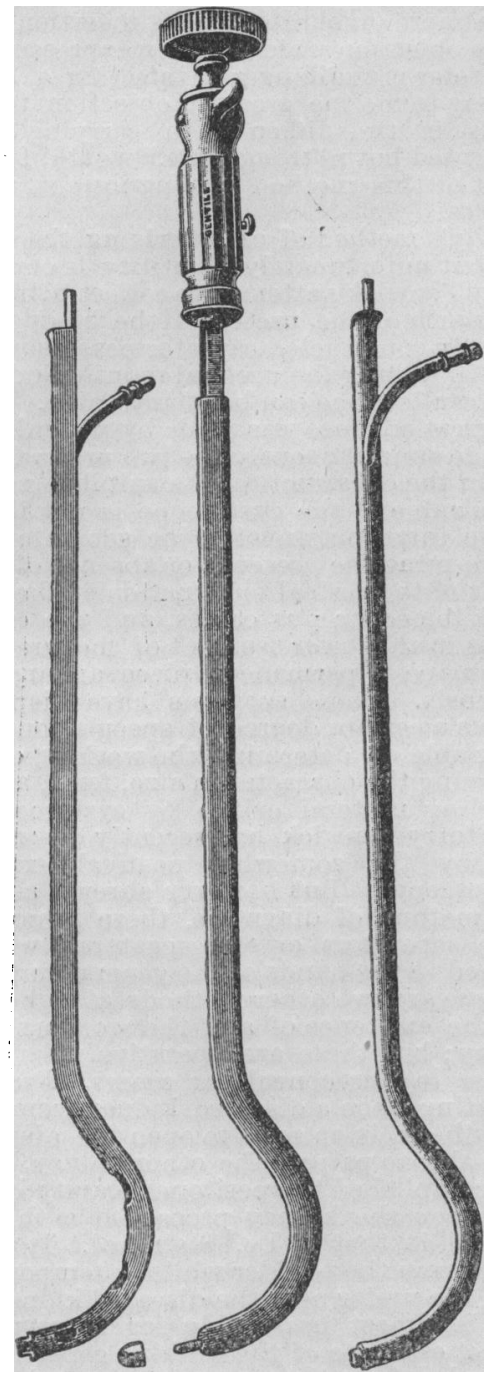

Fig. 1.-The three parts of Luys's instrument (Hartmann and Luys).

fore it has entered the bladder, or by creating a septum in the middle of the bladder, in such manner as to secure that the urine from each ureter is confined to its own side of the bladder, from which it is drawn through a small catheter.

Catheterization of the ureters is not seldom matter of difficulty, and is by no means unattended with danger. It requires for its adept performance much patient practice ; it it is, indeed, so technical a procedure that the majority of surgeons do not make use of it. The creation of a septum in the bladder, adequately dividing it into two cavities, whose contents remain separate, is a problem that for several years past has engaged the attention of those working in this branch of surgery.

It is to Lambotte of Brussels that we are indebted for the first attempt in this direction. In 1890 he constructed an instrument which, though rude in conception, has been the forerunner of those.which to-day are recognized as fulfilling perfectly their object. Lambotte himself soon abandoned the use of his instrument. Harris of Chicago and Downs of Philadelphia were the next to attempt, with greater success, to find a satisfactory method. Harris's instrument, known as the "segregator," depends for its action upon the lifting up of the base of the bladder in the middle line, by the pressure of an instrument introduced into the rectum. This instrument created a hillock or septum in the bladder, and the urine escaping from the ureter formed a pool upon its corresponding side of the bladder. From this pool it was drawn off by a small catheter. This instrument was most ingenious in construction, but in actual working was found not to be strictly reliable.

The first perfectly-efficient instrument was created after some modifications of the original pattern by Dr. G. Luys, of the Hôpital Lariboisière in Paris. It is shown in Fige. I and 2. It consists of three portions, a central portion within

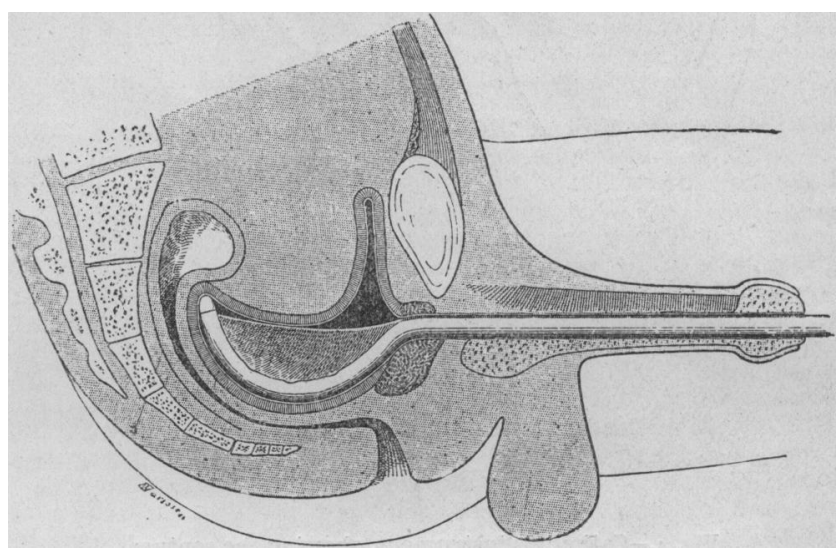

Fig. 2.-The separator of Luys (Hartmann and Luys).

which lies a chain attached at the handle of the instrument to a wheel. This portion, like the lateral parts, is straight to within about 2 in. of the end, where there is a marked curve forming almost the half of a circle. This portion is covered with a thin rubber sheathing. When the screw which works the chain is turned the chain is tightened, and instead of lying in the hollow of the curve of the instrument, it is raised up, forming a diameter instead of a part of the circumference of the circle. The indiarubber sheathing is also raised up, and in this way a septum is formed. The lateral pieces, fitting on to the sides of the central piece, consist of two catheters having several eyes. Each catheter drains its own side of the bladder after the septum has been created.

The whole instrument has somewhat the curve of a beniquié catheter. When viewed sideways, it is seen that the central portion is a little deeper than the lateral portions and can be seen to project a little beyond these both on the concave and on the convex side.

Another instrument with which perfectly satisfactory results may be obtained is that invented by Dr. Cathelin of Paris (Figs. 3 and 4 ). The shape of this model is very nearly the same as that in the ordinary bladder sound. There is a short, sharply-curved beak. The stem of the sound is hollow, and contained within it is the folded indiarubber leaf, which, on liberation, forms the septum dividing the bladder into two parts. The leaf or septum consists of indiarubber fixed on to a pear-shaped spring which forms its margin. This is attached to a rod which runs in the hollow of the sound. When this rod lies in the sound, being pushed home, the indiarubber septum projects from the end; when the rod is pulled upon, the septum is drawn up into the sound. It folds upon itself quite readily.

When the separator is passed, the rod bearing the septum is drawn out to its fullest extent. The instrument is passed, as a rule, without the smallest difficulty. When it is felt to be in the bladder, it is withdrawn until the beak is in close contact with the back of the pubes. The septum is then liberated by pushing home the rod which bears it. A little 
water purposely left in the bladder is allowed to flow away through the instrument, and the urine is then collected from each side.

It is impossible, with the limited experience which I possess, to institute a true comparison between the two instruments. I have certainly found that Luys's instrument, though easy to use in the female, is decidedly difficult to pass in the male, until repeated practice has given one the knack. When the tip of the instrument lies in the bladder the handle should be well depressed at the same time that onward pressure is maintained. In this way it will be found easiest to overcome the undoubted difficulty of introduction. Professor Hartmann, however, has told me that he considers the instrument is easier to use in the male than in the female, and, with frequent practice, this may be so.

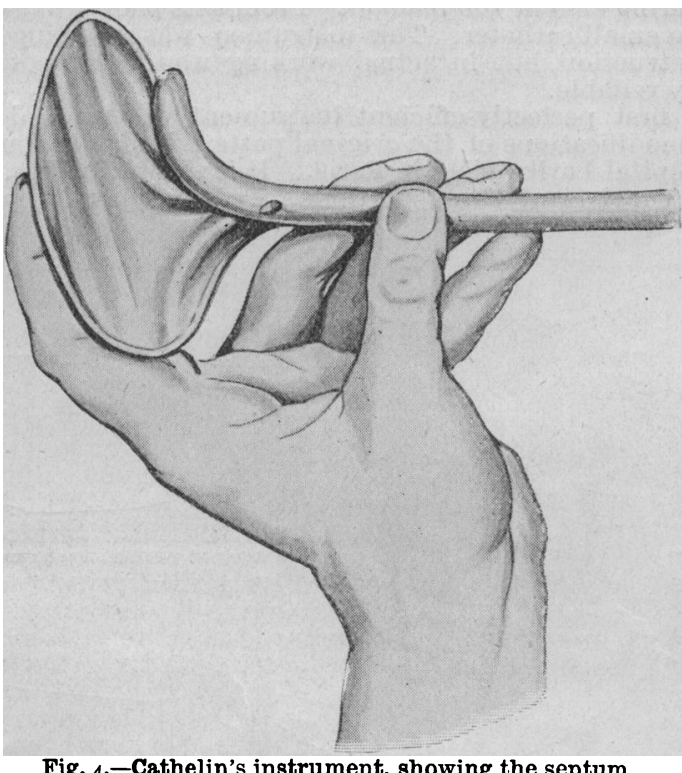

Cathelin's instrument presents no difficulty in the introduction, but it is not quite an easy matter at first to know by touch alone that the septum fits the bladder well. If the bladder is small and the septum be pushed fully into the bladder it will twist to one side, and the partition will be defective. It is, therefore, necessary before using the instrument to ascertain roughly the capacity of the bladder. Various sizes of septa are now made; at first only one was provided.

Dr. Luys's instrument is of no value unless the bladder be fairly normal in size and position. If the base of the bladder is infiltrated with growth, spreading from the cervix of the uterus, for example, or if the bladder be distorted by the traction or pressure of a fibroid or an ovarian cyst, the curve of Luys's instrument cannot be made accurately to fit the bladder. In such circumstances it may be difficuit to use Cathelin's instrument, but it is certainly less likely to be so.

My present opinion is in favour of the use of Luys's instrument for the female and of Cathelin's for the male, but I am prepared to admit that a more extended experience may modify my opinion.

There can be no doubt that both instruments are of great practical value. I propose shortly to publish a complete series of observations, but meanwhile I may call attention to two cases reported by me in the British Medical Journal for April 3oth, in which great help was afforded by the separation of the urines.

\section{A NOTE ON DR. CATHELIN'S URINE SEPARATOR.}

BY J. LYNN THOMAS, C.B., F.R.C.S.ENG.,

Surgeon, Cardiff Infirmary; Consulting Surgeon, Hamadryad Hospita], Porth Hospital, Bridgend Cottage Hospital, and Cardiff Provident Dispensary.

DURING the last quarter of a century the progress of urogenital diseases from a surgical point of view has been very great, but until quite recently a method for the separation of urine from each kidney had not been brought within the reach of the general surgeon, although one has recognized the circumstance that the surgeon who specializes in these diseases had a certain amount of success.

As far as I know, the first inspiration towards progress in determining the functionating value of a kidney was directed to tapping its efferent tube-the ureter. The inventive eye of the clinician seems to have been riveted to this field for many years. The outcome of having such a limited horizon has been the production of different types of ureteral catheters. In 1894 I procured from Leiter in Vienna a posterior cystoscope+ureter catheter. After many attempts I managed to introduce it into the ureter twice only. The Nitze's anterior cystoscope ureter catheter has one advantage over the posterior one in that the angle at which the catheter is projected from the cystoscope towards the ureteral orifice is much more favourable for its insertion into the ureter.

One objection which is often expressed against catheterizing the ureter is the danger of infecting a healthy one, but what appears to me the greatest objection to this method of diagnosis is the difficulty in carrying it out. "Something attempted but nothing done," would, I think, summarize the result of this method of diagnosis in a considerable number of cases.

Kelly's method of catheterizing the ureter is an excellent one, but unfortunately its utility is confined to one sex. Mr. Hurry Fenwick's attempt to collect urine by means of securing the mouth of the ureter in the bladder by sucking it into a properly-constructed catheter possesses the element of guesswork in finding the ureteral mouth, and on that account positive results alone can be of any value.

A great advance was made by widening the horizon so as to include simultaneously the two ureteral orifices for investigation in the construction of a suitable instrument.

The value of the cystoscope is not in the least diminished by the introduction of urine separators. Its use in quickly determining the presence or absence of the rhythmical movements of the vesical termination of the ureters, the side from which blood or pus comes, and the existence of growths or stones in the lower segment of the ureter, will ensure for the cystoscope a permanent place among our instruments for diagnosis. Some surgeons have displayed enthusiasm, as well as a certain degree of speculation, with regard to their being able to determine the working capacity of a kidney by observing the character in size, form, and colour of its corresponding ureteral orifice by cystoscopic examination, and Mr. Hurry Fenwick has recently described such an examination by the somewhat poetical expression of "ureteric meatoscopy." But however shrewd a guess can be made by this method of diagnosis, there is no doubt that the new urine separators or "segregators" will soon be a popular method in the hands of the general surgeon.

There are two other methods at our disposal for determining the existence of and the working capacity of the other kidney; but these are operative means, and therefore are of no use in our consulting rooms. Professor Kocher, whilst operating upon a diseased kidney from the loin, extends forward the incision so as to open the abdominal cavity in order to be able to palpate the other kidney. After this manœuvre is accomplished the peritoneal cavity is closed and the operation upon the kidney proceeded with. The other operative method is that of Dr. Steinthal. It consists of collecting urine from the bladder whilst a temporary ligature is placed upon the ureter near the diseased kidney.

It is almost impossible for surgeons to be able to form a correct estimate of the working capacity of a kidney which is distended from the presence of a calculus, or a kink of the ureter or other causes, and it is common experience to find urine pouring out of the loin in cases of drainage of diseased kidneys which showed but a mere membrane of secreting tissue lining their capsule. One of my colleagues last winter related to our Cardiff Medical Society such a case of extensive destruction of kidney from the presence of numerous calculi, and he considered it wise to remove an organ which apparently was practically useless. Subsequently the patient gradually developed uraemic symptoms and died. It was discovered post mortem that the other kidney was small and disorganized-that it possessed no working capacity. Surgical calamities of this character have occurred on many occasions, and the addition of a simple method of diagnosis by means of which similar tragedies can be avoided will be an invaluable boon.

Last February I procured Dr. Cathelin's instrument from Collin; its mechanism appeared to me to be better than that 